\title{
The ignition and burning of mixed compositions with heavy fillers
}

\author{
Alexander Zhukov, Valeriy Kuznetsov, and Sergey Timoshensky* \\ National Research Tomsk State University, Tomsk, Russia
}

\begin{abstract}
The problem of increasing the efficiency of metal components in the composition of high-energy fuel compositions by complete or partial replacement of aluminum by metal borides is considered. In this paper, we present and analyze the experimental results of the investigation of the ignition and combustion of mixtures based on a hydrocarbon and active binder with inorganic oxidants and energy-intensive fillers.
\end{abstract}

\section{Introduction}

A promising trend of solution to the problem of increasing the efficiency of the metal componentsas part of high energy fuel compositions is seen as full or partial substitution of aluminum for high-energy borides of metals. In this case, the high energy characteristics of metallic fuel compositions is achieved due to the increased heat of combustion components and by increasing the chemical conversion rate of metals into oxides [1,2].

It is known [2] that the heat of combustion of boron is almost twice the calorific value of aluminum and the oxidation onset temperature of boron is much lower than that of aluminum. However, due to the specific properties of boron oxide $\mathrm{B}_{2} \mathrm{O}_{3}$ (high value of boiling temperature and viscosity of liquid oxide) the oxidation degree of elemental boron at its introduction into the fuel is small. Even in oxygen-containing environment, the combustion efficiency of boron is only $26,5 \%(3)$. One of the solutions to implement high heat of combustion of boron in the fuel composition is its use in the form of borides of aluminum [3, 4].

Borides of aluminum has low binding energy between the atoms $\mathrm{Al}$ and $\mathrm{B}(67 \mathrm{~kJ} / \mathrm{mol})$. Therefore, they can be considered as alloys, and in the preflame area, they will decompose into $\mathrm{Al}$ and $\mathrm{b}$, and separately enter into a chemical reaction with oxygen. Aluminum that forms high temperature combustion products, will contribute to the efficient combustion of boron $[5,6,7]$.

\footnotetext{
*Corresponding author: Timosh13@mail.ru
} 


\section{Results of calculations}

In the present work the results of experimental studies of ignition and burning of mixed compositions on the basis of hydrocarbon (HB) and active (AB) binder with inorganic oxidizing agents and heavy fillers $\left(\mathrm{Al}, \mathrm{B}, \mathrm{AlB}_{2}, \mathrm{AlB}_{12}, \mathrm{TiB}_{2}\right)$ are presented.

As a hydrocarbon binder $(\mathrm{HB})$ the divinyl rubber solution in the petroleum oil in a ratio of 20/80 (SKDM-80) was used. Active binder (AB) consists of a solution of the methylprednisolone copolymer in eutectic mixture of nitrate ester with nitramines (NWTASPECTS) [8]. Oxidizers were ammonium perchlorate bidispersed fraction $(60 \%$ size 165-315 microns and 40\% less than 50 microns) and ammonium nitrate with a particle size of 165-315 microns. The coefficient of excess for oxidant of model compounds on HB is 0.5 , and on $\mathrm{Al}-0.64$. Samples of cylindrical shape were produced by the method of through passage pressing. The diameter of samples is $10 \mathrm{~mm}$. Thecontent of components in the model formulations is given in table 1

Table 1. The compositions of energy-intensive compositions.

\begin{tabular}{|c|c|c|c|c|c|}
\hline \multirow{2}{*}{ Composition } & \multicolumn{5}{|c|}{ The content of components, wt.\% } \\
\cline { 2 - 6 } & PHA & ON & SKDM-80 & $\begin{array}{c}\text { NWT- } \\
\text { ASPECTS }\end{array}$ & Metal, mark \\
\hline Al & $69.0_{(\mathrm{b} / \mathrm{d})}$ & & 16.0 & & $15.0 \mathrm{Al}$ \\
\hline A2 & $74.0_{(\mathrm{b} / \mathrm{d})}$ & & 11.0 & & $15.0 \mathrm{~B}$ \\
\hline A3 & $71.4_{(\mathrm{b} / \mathrm{d})}$ & & 13.6 & & $15.0 \mathrm{AlB}_{2}$ \\
\hline A4 & $73.2_{(\mathrm{b} / \mathrm{d})}$ & & 11.8 & & $15.0 \mathrm{AlB}_{12}$ \\
\hline A5 & $70.2_{(\mathrm{b} / \mathrm{d})}$ & & 14.8 & & $15.0 \mathrm{TiB}_{2}$ \\
\hline B1 & 21.3 & 49.8 & 13.9 & & $15.0 \mathrm{Al}$ \\
\hline B2 & 22.5 & 52.5 & 10.9 & & $15.0 \mathrm{~B}$ \\
\hline B3 & 21.9 & 51.3 & 11.8 & & $15.0 \mathrm{AlB}_{2}$ \\
\hline B4 & 22.5 & 52.3 & 10.0 & & $15.0 \mathrm{AlB}_{12}$ \\
\hline B5 & 21.6 & 50.4 & 13.0 & & $15.0 \mathrm{TiB}_{2}$ \\
\hline C1 & 15 & 35 & & 20 & $30 \mathrm{Al}$ \\
\hline C2 & 18 & 42 & & 25 & $15 \mathrm{~B}$ \\
\hline C3 & 15.6 & 36.4 & & 23 & $25 \mathrm{AlB}_{2}$ \\
\hline C4 & 17.4 & 40.6 & & 25 & $17 \mathrm{AlB}_{12}$ \\
\hline C5 & 15.9 & 37.1 & & 23 & $24 \mathrm{TiB}_{2}$ \\
\hline
\end{tabular}

Studies of the ignition of model mixed compositions were performed in air at atmospheric pressure through heat flux radiation exposure from a xenon lamp in an optical furnace "Uranium -1" [9].

The radiation from the xenon lamp is focused by an elliptical mirror into a spot with a $12 \mathrm{~mm}$ diameter. The installation provides at least $95 \%$ light flux stability in the radiation intensity range $Q=(5 \div 400) \mathrm{W} / \mathrm{cm}^{2}$. The intensity of thermal radiation was measured with a copper calorimeter with an error not exceeding $10 \%$. The ignition delay time, $t_{\text {ign }}$, was determined by the appearance of a flame recorded by means of photodiodes on an H117/1 oscilloscope. The error in measuring the delay time of ignition of the mixture compositions did not exceed $7 \%$.

For all compositions (Table 1), the values of the ignition delay time from the intensity of thermal radiation in the range $(15 \div 100) \mathrm{W} / \mathrm{cm}^{2}$ are determined. 
Since in the investigated range of heat flux experimental data, presented in logarithmic coordinates, reasonably well fit to a slope line, which correspond to the exponent in the chart of $t_{i g n}=a q^{-n}$, the experimental results can be conveniently represented in the form of parameters ( $-n$ and $t_{i g n}$ for a given $q$ ) in table 2 .

Table 2. Characteristics of ignition and combustion of the mixed compositions.

\begin{tabular}{|c|c|c|c|c|c|c|}
\hline Composition & $\begin{array}{c}t_{\text {ignn, }} \mathrm{s} \\
\text { with } \\
54 \mathrm{~W} / \mathrm{cm}^{2}\end{array}$ & $\begin{array}{c}|-n| \\
t_{3}=A q^{-n}\end{array}$ & $\begin{array}{c}Q, \mathrm{~J} / \mathrm{cm}^{2} \\
\text { with } \\
54 \mathrm{~W} / \mathrm{cm}^{2}\end{array}$ & $K_{I}=Q_{a} / Q_{i}$ & $U, m m / s$ & $\boldsymbol{K}_{I}=\boldsymbol{U}_{I} / \boldsymbol{U}_{A c}$ \\
\hline A1 & 0.33 & 1.61 & 17.8 & 1.00 & $1.06 \pm 0.01$ & 1.00 \\
\hline $\mathrm{A} 2$ & 0.21 & 1.45 & 11.3 & 1.57 & $1.71 \pm 0.02$ & 1.61 \\
\hline A3 & 0.25 & 1.55 & 13.5 & 1.32 & $1.15 \pm 0.01$ & 1.08 \\
\hline A4 & 0.34 & 1.25 & 18.4 & 0.97 & $1.08 \pm 0.02$ & 1.02 \\
\hline A5 & 0.55 & 1.36 & 29.7 & 0.60 & $1.21 \pm 0.04$ & 1.14 \\
\hline B1 & 0.50 & 1.58 & 27.0 & 1.00 & $0.20 \pm 0.02$ & 1.00 \\
\hline B2 & 0.24 & 1.50 & 13.0 & 2.08 & $1.00 \pm 0.02$ & 5.00 \\
\hline B3 & 0.38 & 1.50 & 20.5 & 1.32 & $0.60 \pm 0.02$ & 3.00 \\
\hline B4 & 0.39 & 1.45 & 21.1 & 1.28 & $0.33 \pm 0.02$ & 1.65 \\
\hline B5 & 0.62 & 1.43 & 33.5 & 0.81 & $0.18 \pm 0.02$ & 0.9 \\
\hline $\mathrm{C} 1$ & 0.75 & 1.48 & 40.5 & 1.00 & $1.47 \pm 0.07$ & 1.00 \\
\hline $\mathrm{C} 2$ & 0.45 & 1.20 & 24.3 & 1.67 & $1.93 \pm 0.07$ & 1.31 \\
\hline $\mathrm{C} 3$ & 0.44 & 1.27 & 23.8 & 1.70 & $2.40 \pm 0.20$ & 1.63 \\
\hline $\mathrm{C} 4$ & 0.46 & 1.20 & 24.8 & 1.63 & $1.42 \pm 0.08$ & 0.96 \\
\hline $\mathrm{C} 5$ & 0.69 & 1.25 & 31.3 & 1.29 & $0.31 \pm 0.03$ & 0.21 \\
\hline
\end{tabular}

In addition, the table shows the values of energy required for ignition (Q), the values of the stationary burning rate of compositions in the air at atmospheric pressure (U), the performance parameters of the boron and borides chemical activity in comparison with aluminum under the conditions of ignition (K1) and combustion (K2).

\section{Conclusion}

Analysis of experimental results showed that the direct correlation of the ranks of the compounds reactivity in terms of ignition and combustion is not observed. However, it is 
impressive to see that in the investigated conditions, the boron and the borides of aluminum accelerate the process of ignition and combustion of model compositions.

This work was supported financially by the Ministry of Education and Science of the Russian Federation in terms of state order, project code 9.9036.2017.

\section{References}

1. V. N. Aleksandrov, V. M. Byatskevich, V. K. Verkholomov Integral ramjet air-jet engines on solid fuels (ICC Akademkniga, Moscow, 2006) [in Russian]

2. M. K. King, Journal of spacecraft and Rockets, 19, 4 (1982)

3. J.Lui, J.Xi, W. Yang, Acta Astronaut 96, 89 (2014)

4. S. Xu, Yu. Chen, X. Chen, D. Wu, and D. Lui, Combust. Explos. Shock Waves. 52, 3 (2016)

5. G. Young, K. Sullivan, M.R. Zachariah, K. Yu, Combust. Flame 156, 322 (2009)

6. D. A. Yagodnikov, A. V. Voronetskii, and V. I. Sarab'ev, Combust. Explos. Shock Waves. 52, 3 (2016)

7. A.B. Vorozhtsov, Novel micro-and nanofuels: Production characterization, and applications for High-Energy materials (Springer International Publishing, Switzerland, 2017)

8. V. F. Komarov, N. I. Popok, G. V. Sakovich, Fundamental and applied problems of technical chemistry (Science, Novosibirsk, 2011)

9. V. A. Arkhipov, S. E. Bondarchuk, A. G. Korotkih, V. T. Kuznetsov, Combustion explosion, and shock waves, 48, 5 (2012) 